\title{
Reconstrução marginal de pálpebras utilizando enxerto de palato duro
}

\author{
Margin eyelid reconstruction with hard palate graft
}

\author{
Tiana Gabriela Burmann ${ }^{1}$ \\ Ítalo Marcon ${ }^{2}$ \\ Tiago Rizzato ${ }^{3}$ \\ Karin Scheid $^{4}$
}

Trabalho realizado no Serviço de Oftalmologia da Irmandade da Santa Casa de Misericórdia de Porto Alegre - ISCMPA, Fundação Faculdade Federal de Ciências Médicas de Porto Alegre - FFFCMPA - Porto Alegre (RS) - Brasil

Doutora em Oftalmologia, preceptora do Setor de Plástica Ocular do Serviço de Oftalmologia da Irmandade da Santa Casa de Misericórdia de Porto Alegre - ISCMPA e Fundação Faculdade Federal de Ciências Médicas de Porto Alegre - FFFCMPA - Porto Alegre (RS) - Brasil.

${ }^{2}$ Professor livre-docente, Doutor em Oftalmologia e Chefe do Serviço de Oftalmologia da ISCMPAe daFFFCMPA - Porto Alegre (RS) - Brasil.

${ }^{3}$ Estagiário do Serviço de Oftalmologia da ISCMPA e da FFFCMPA - Porto Alegre (RS) - Brasil.

Estagiária do Serviço de Oftalmologia da ISCMPA e da FFFCMPA - Porto Alegre (RS) - Brasil.

Endereço para correspondência: Tiana Gabriela Burmann - Av. Nilo Peçanha, 724 - Sala 401 - Porto Alegre (RS) CEP 90470-000

E-mail: tianaburmann@terra.com.br

Recebido para publicação em 23.09.2007

Última versão recebida em 25.11.2007

Aprovação em 11.01.2008

\begin{tabular}{|l|}
\hline RESUMO \\
\hline Objetivo: Avaliar os benefícios e complicações do uso do palato duro na \\
reconstrução de pálpebras inferiores acometidas por carcinomas ba- \\
socelulares extensos. Métodos: Revisão da literatura e descrição da téc- \\
nica utilizada no Setor de Oculoplástica do Hospital Santa Casa de \\
Porto Alegre. Resultados: O enxerto de palato duro é um excelente \\
substituto da lamela posterior na reconstrução palpebral, pois apresenta \\
os benefícios da superfície mucosa, associado ao fato de atuar como \\
suporte semi-rígido. Conclusão: A técnica de sanduíche utilizando palato \\
duro mostrou-se eficiente, com um resultado estético e funcional bastante \\
satisfatório.
\end{tabular}

Descritores: Palato duro/transplante; Mucosa bucal/transplante; Transplante autólogo; Pálpebras/cirurgia; Carcinoma, basal cell

\section{INTRODUÇÃO}

A busca pela técnica capaz de reconstruir uma pálpebra e satisfazer não apenas a anatomia palpebral, mas também a sua função tem levado à utilização de diversos tecidos. Na reconstrução palpebral, três elementos são importantes: a pele, a estrutura de sustentação e a mucosa.

A reconstrução palpebral com a técnica de sanduíche compreende um retalho local de avançamento de músculo orbicular entre dois enxertos livres. A estrutura semi-rígida pode ser tarso, esclera preservada, cartilagem auricular, septo nasal ou palato duro ${ }^{(1-5)}$. A superfície externa é reconstruída através de um enxerto livre de pele.

Este estudo tem por objetivo avaliar os benefícios e complicações da técnica de sanduíche, utilizando o palato duro como substituto da lamela posterior.

\section{MÉTODOS}

Foram selecionados 9 pacientes que apresentavam lesões palpebrais clinicamente suspeitas de neoplasia, extensas, comprometendo mais de $50 \%$ da margem palpebral inferior.

Os pacientes foram operados pelo mesmo cirurgião oculoplástico, sob anestesia local e sedação e as margens da lesão foram avaliadas pela técnica de congelação. A reconstrução palpebral foi realizada no mesmo ato cirúrgico mediante a confirmação anátomo-patológica de termos margens livres e seguras.

A técnica de sanduíche, também denominada de reconstrução topográfica, foi utilizada na reconstrução das pálpebras desses pacientes. A lamela 
posterior foi reconstruída com enxerto de palato duro, a lamela anterior com pele da pálpebra superior ipsi ou contralateral, e, entre os dois enxertos, foi avançado um retalho de músculo orbicular (incisões verticais no músculo facilitaram o avançamento) (Figura 1).

O sítio doador de palato foi limitado pelas pregas palatinas anteriormente e pela junção do palato duro com o mole posteriormente. Alguns cuidados foram observados: evitou-se a retirada de enxertos muito espessos; manteve-se distância da linha média e do forame palatino maior e promoveu-se uma boa cauterização local (Figura 1).

Na técnica realizada nessa série de casos, utilizou-se enxertos (palato e pele) um pouco maiores que o tamanho do defeito causado pela retirada da lesão. Além disso, foi colocado o curativo de Brown e a sutura de Frost nas primeiras 48 horas de pós-operatório.

\section{RESULTADOS}

Participaram do estudo 9 pacientes, 4 do sexo masculino e 5 do feminino, com faixa etária entre 62 e 79 anos. Todos os pacientes apresentavam carcinomas basocelulares extensos das pálpebras inferiores com comprometimento do canalículo inferior em 1 caso.

Não foram observadas complicações no sítio doador de palato duro e também não ocorreram complicações nos sítios doadores de pele.

A pele utilizada para reconstruir a lamela anterior apresentou-se com boa cicatrização e resultado estético. Além disso, não se observou casos de necrose do enxerto nesses pacientes.

A retração do enxerto foi regra, no entanto discreta na maioria dos pacientes, exceto em um caso onde houve retração moderada que comprometeu o resultado estético final.

Os pacientes foram acompanhados por um período médio de 18 meses (entre 12 e 36 meses) e não apresentaram, nesse período, sinais de recidiva no local.

\section{DISCUSS $\tilde{A} O$}

A utilização do palato duro foi inicialmente sugerida na reconstrução de pálpebras acometidas por tumores, em 1985, por Siegel ${ }^{(6)}$. Atualmente, não se restringe apenas a reconstru-
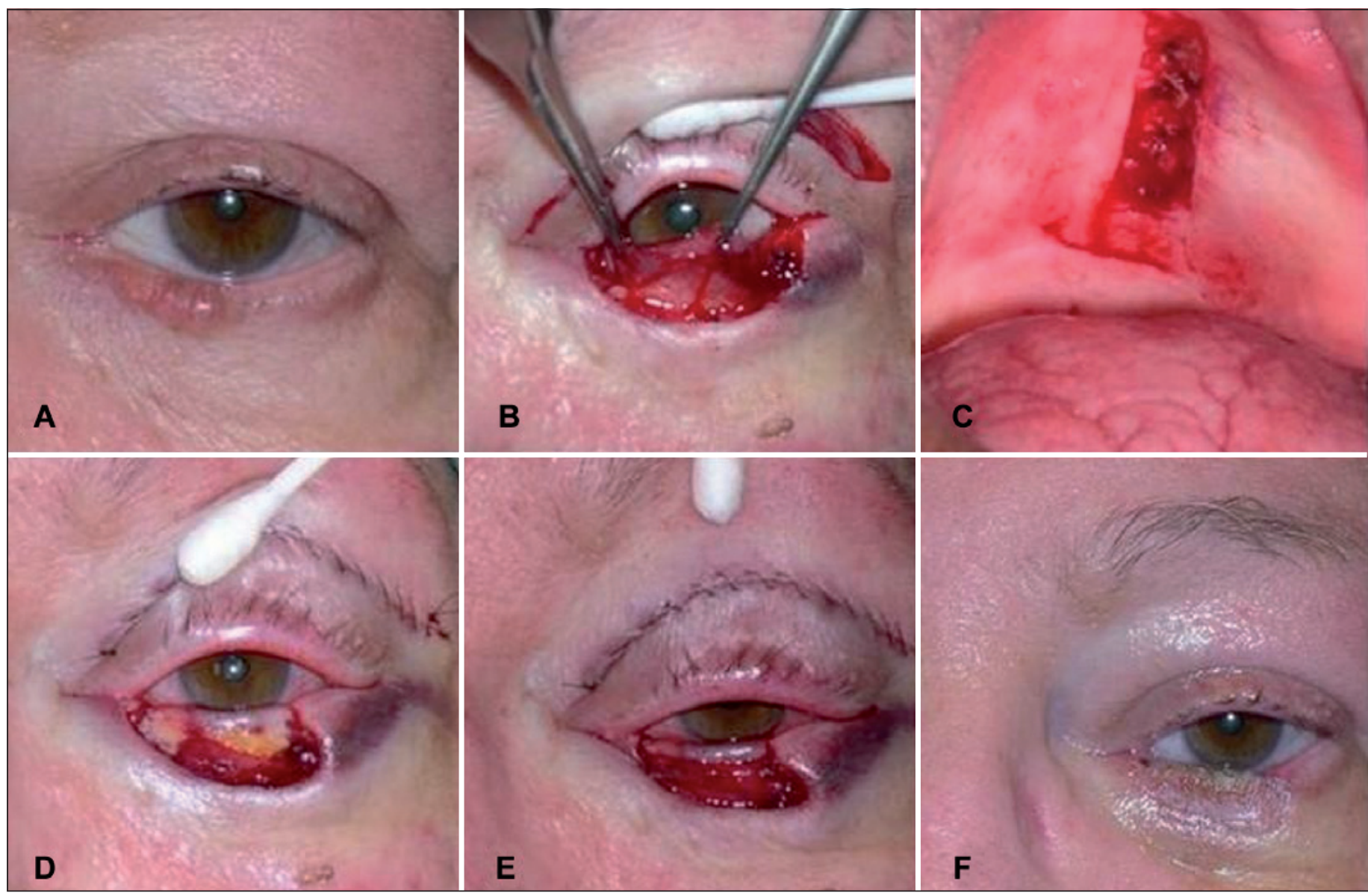

Figura 1 - Técnica utilizada: A) Pré-operatório; B) Defeito causado pela retirada do carcinoma basocelular da pálebra inferior esquerda e preparação do retalho de músculo orbicular através de incisões verticais. Retirada de enxerto de pele da pálpebra superior para reconstrução da lamela anterior; C) Sítio doador de palato duro, poupando a linha medial e promovendo cuidadosa cauterização; D) Sutura do enxerto de palato duro com vicryl 6.0 para reconstruir a lamela posterior; E) Sutura do orbicular com vicryl 6.0 e da pele com nylon 6.0; F) Pós-operatório de 2 semanas. 
ção de pálpebras acometidas por tumores palpebrais, mas também é utilizado para tratar uma série de desordens incluindo retração da pálpebra inferior pós-blefaroplastia, entrópio cicatricial, retração palpebral secundária à orbitopatia de Graves, lagoftalmo secundário à cirurgia de ptose paralítica e reconstrução de cavidades anoftálmicas ${ }^{(5,7-9)}$.

$\mathrm{O}$ palato duro tem a vantagem de possuir uma superfície regular, funcionar como um suporte nas reconstruções palpebrais e permitir a retirada de enxertos grandes, possibilitando a correção de defeitos extensos da margem palpebral, sem causar dano ao sítio doador ${ }^{(4)}$. Além disso, trata-se de um tecido autógeno, retrai pouco e o sítio doador tem um curto período de cicatrização $^{(6,10-11)}$. Estudos sugerem que a contração média do enxerto de palato duro seja aproximadamente $16 \%^{(11)}$.

A retirada do enxerto requer conhecimento da anatomia local, devendo-se evitar incisões muito profundas que possam causar sangramentos importantes e lesar o periósteo, comprometendo a cicatrização ${ }^{(1)}$.

Os pacientes selecionados nessa amostra apresentavam carcinomas basocelulares que comprometiam amplamente a margem da pálpebra inferior. A utilização desse tipo de enxerto em pálpebras superiores pode causar abrasões corneanas intratáveis devido à metaplasia do epitélio ${ }^{(7)}$.

Existem diversas complicações descritas com o enxerto de palato duro e estas podem acometer o sítio doador (sangramento,

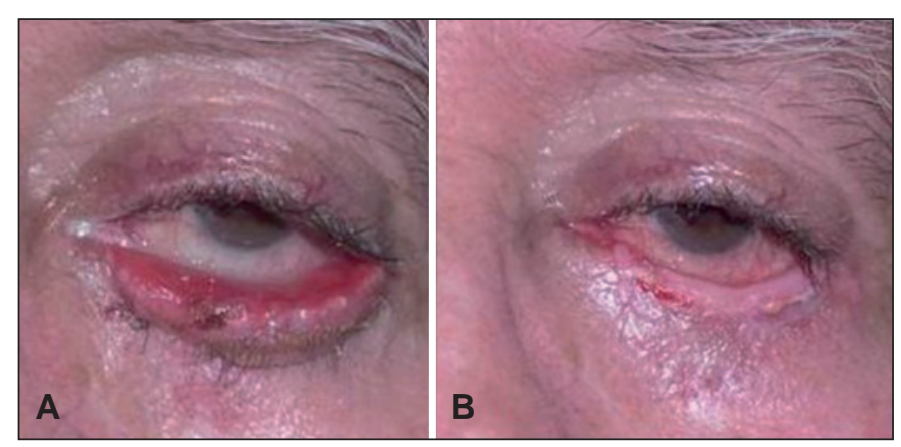

Figura 2 - Retração palpebral significativa, comprometendo o resultado estético: A) Pré-operatório; B) Pós-operatório desconforto local, fístula oro-nasal e infecções) e o receptor (necrose, queratinização e secreção mucóide persistente produzida pelas glândulas salivares presentes no enxerto) ${ }^{(1,12-13)}$. Nesse estudo observou-se um caso de secreção mucóide persistente e outro de retração significativa do enxerto, esse último tratandose de uma pálpebra comprometida na sua totalidade (Figura 2). Nessa série de casos não foi observada necrose dos enxertos e complicações relacionada aos sítios doadores.

Queixas de desconforto e sensação de corpo estranho são comuns e usualmente transitórias. Observamos que enxertos discretamente maiores que o defeito podem minimizar o risco de retração, observação essa já apontada em outros estudos ${ }^{(14)}$.

A exérese dos tumores palpebrais com a técnica de congelação e imediata reconstrução parece apresentar menor índice de recidivas. Outra opção é a excisão de tumores malignos microscopicamente controlada (técnica de Mohs), que propicia um alto índice de cura e preservação de tecidos ${ }^{(15)}$.

A reconstrução da margem palpebral pela técnica de sanduíche, utilizando enxerto do palato, retalho de músculo orbicular e enxerto de pele, confere bons resultados funcionais. A pele, especialmente palpebral, costuma ter a textura e a cor muito semelhantes, por isso a estética não fica comprometida (Figura 3).

\section{CONCLUSÃO}

O palato funciona como um ótimo substituto para a lamela posterior porque tem uma superfície mucosa, permitindo o deslizamento sobre a superfície do globo; é abundante e proporciona um suporte desejável. Nessa série de casos, a utilização da técnica de sanduíche mostrou-se eficiente e com boa reabilitação estética.

\section{ABSTRACT}

Purpose: To investigate the advantages and the complications of the use of hard palate graft in the reconstruction of the inferior eyelids with large basocelular carcinoma. Methods:
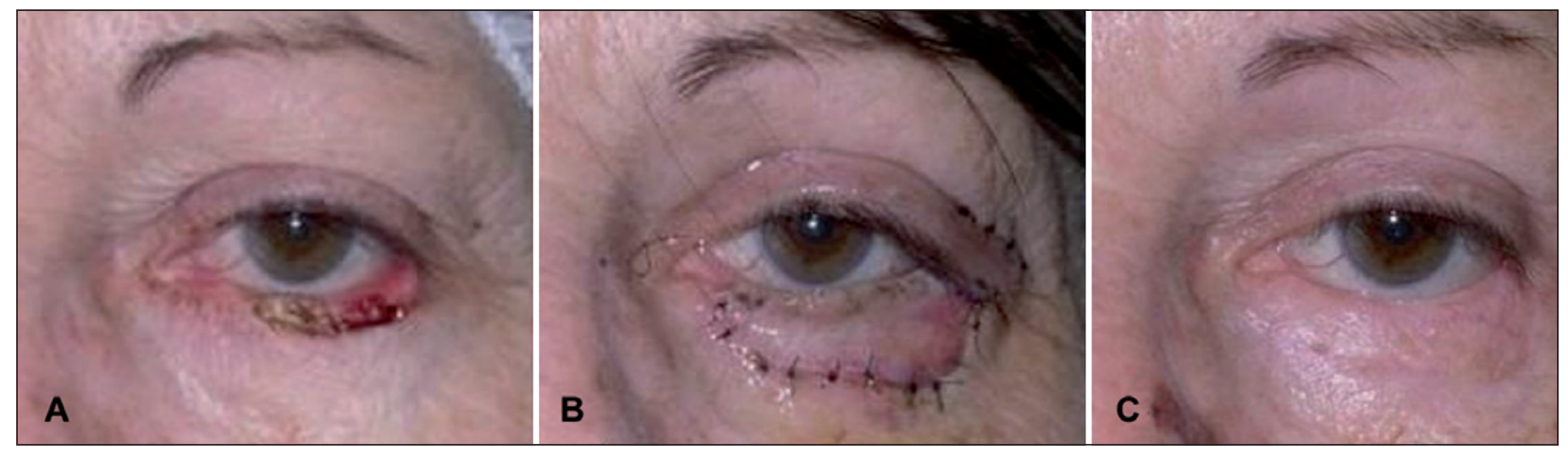

Figura 3 - Resultado estético adequado: A) Pré-operatório; B) Pós-operatório precoce; C) Pós-operatório tardio 
Review of specialized articles and report of the technique used in the Oculoplastic Department of the "Hospital Santa Casa de Porto Alegre". Results: The hard palate graft is an excellent replacement for posterior lamellar defects in eyelid reconstruction, because it presents the benefit of a mucous layer in addition to a semirigid support. Conclusion: The sandwich technique using hard palate was shown to be efficient, with good functional and esthetic results.

Keywords: Palate, hard/transplantation; Mouth mucosa/transplantation; Transplantation, autologous; Eyelids/surgery; Carcinoma basocelular

\section{REFERÊNCIAS}

1. Fernandes JB, Nunes TP, Matayoshi S, Moura EM. Enxerto de mucosa do palato duro: complicações na área doadora - relato de casos. Arq Bras Oftalmol. 2003;66(6):884-6.

2. Yildirim S, Gideroglu K, Akoz T. Application of helical composite sandwich graft for eyelid reconstruction. Ophthal Plast Reconstr Surg. 2002;18(4):295-300.

3. Callahan A. Reconstruction of the eyelids with cartilage and mucosa from the nasal septum. Trans Ophthalmol Soc U K. 1976;96(1):39-44.

4. Perry MJ, Langtry J, Martin IC. Lower eyelid reconstruction using pedicled skin flap and palatal mucoperiosteum. Dermatol Surg. 1997;23(5):395-7; discussion 397-8.
5. Cohen MS, Shorr N. Eyelid reconstruction with hard palate mucosa grafts. Ophthal Plast Reconstr Surg. 1992;8(3):183-95. Comment in: Ophthal Plast Reconstr Surg. 1994;10(1):64-5.

6. Siegel RJ. Palatal grafts for eyelid reconstruction. Plast Reconstr Surg. 1985; 76(3):411-4.

7. Goldberg RA, Joshi AR, McCann JD, Shorr N. Management of severe cicatricial entropion using shared mucosal grafts. Arch Ophthalmol. 1999;117(9): 1255-9.

8. Patel BC, Patipa M, Anderson RL, McLeish W. Management of postblepharoplasty lower eyelid retraction with hard palate grafts and lateral tarsal strip. Plast Reconstr Surg. 1997;99(5):1251-60.

9. Ito O, Suzuki S, Park S, Muneuchi G, Kawazoe T, Saso Y, et al. Usefulness of palatal mucoperiosteal grafts for artificial eye socket contracture. Ann Plast Surg. 2003;51(3):278-82.

10. Kersten RC, Kulwin DR, Levartovsky S, Tiradellis H, Tse D. Management of lower-lid retraction with hard palate mucosa grafting. Arch Ophthalmol. 1990;108(9):1339-43.

11. Sullivan SA, Dailey RA. Graft contraction: a comparison of acellular dermis versus hard palate mucosa in lower eyelid surgery. Ophthal Plast Reconstr Surg. 2003;19(1):14-24.

12. Kim JW, Kikkawa DO, Lemke BN. Donor site complications of hard palate mucosal grafting. Ophthal Plast Reconstr Surg. 1997;13(1):36-9.

13. Pelletier CR, Jordan DR, Brownstein S, Li S. An unusual complication associated with hard palate mucosal grafts: presumed minor salivary gland secretion. Ophthal Plast Reconstr Surg. 1998;14(4):256-60.

14. Leibovitch I, Malhotra R, Selva D. Hard palate and free tarsal grafts as posterior lamella substitutes in upper lid surgery. Ophthalmology. 2006; 113(3):489-96.

15. Ceilley RI, Anderson RL. Microscopically controlled excision of malignant neoplasms on and around eyelids followed by immediate reconstruction. J Dermatol Surg Oncol. 1978;4(1):55-62. 